\title{
Manufacturing productivity and energy efficiency: a stochastic efficiency frontier analysis
}

\author{
Huanyi Shui, Xiaoning Jin*, ${ }^{\dagger}$ and Jun Ni \\ Department of Mechanical Engineering, University of Michigan, Ann Arbor, MI, USA
}

\section{SUMMARY}

This paper presents a mathematical model to estimate both production frontier and energy demand frontier, and evaluate the energy efficiency in the automotive manufacturing sector using plant-level production and utility consumption data. By using the stochastic frontier analysis, two models - an output efficiency model (production frontier) and an input efficiency model (energy demand frontier) - are developed to analyze the plant's energy efficiency performance relative to the 'best practice' among peers. Both the structure and parameters of two stochastic frontier functions are identified to understand the relationship between production inputs (e.g., utilities and plant-specific variables) and the overall productivity. A case study of a set of automotive engine manufacturing plants is conducted and shows that electricity has higher efficiency than other forms of utility in those production-related activities, and the regional and climate factors have significant impacts on energy efficiency. The models provide a way to measure how far from the production frontier as well as how far from the energy demand frontier the plant is. The results also provide useful information about the inefficient energy components in manufacturing facilities. The opportunities of improving plant-level efficiency in automotive manufacturing plants can be revealed by the results. Copyright (C) 2015 John Wiley \& Sons, Ltd.

\section{KEY WORDS}

Stochastic frontier analysis; energy efficiency; benchmarking

Correspondence

*Xiaoning Jin, Department of Mechanical Engineering, University of Michigan, Ann Arbor, MI, USA.

†E-mail: xnjin@umich.edu

Received 16 September 2014; Revised 17 April 2015; Accepted 5 June 2015

\section{INTRODUCTION}

With the increasing costs of energy resources, manufacturing with higher energy efficiency has become increasingly prioritized for the next-generation manufacturing in the United States. For U.S. automotive manufacturers, energy consumption has a significant impact on production costs and competitiveness. The energy consumption associated with the U.S. automotive enterprises has been estimated at over 850 quadrillion Joule per year [1]. Energy expenditures comprise approximately $1 \%$ of total vehicle production costs [2] and have continuously increased during the past decades.

While today's automotive manufacturing facilities are modern and relatively efficient, there still exist significant opportunities to reduce energy demand through better understanding of energy use, energy management and energy-efficient manufacturing process innovation. Efficient-energy utilization in manufacturing industries is widely believed as a practical approach to achieve significant cost savings as well as reduction of environmental emission [1]. Therefore, increasing economic and legislative pressures have been put on the U.S. automotive manufacturing industry for efficiency improvement, as it seeks to increase its competitive edge on the global market. The automotive manufacturing industry is also motivated to explore new ways to reduce the intensity of energy consumption as well as the impacts of energy cost volatility on its total manufacturing costs by investing in energyefficient technology.

The majority of energy demand in automotive manufacturing is met by four types of utilities - electricity, natural gas, water and compressed air. This paper attempts to evaluate the energy efficiency in manufacturing plants with the consumption data of these four utilities because they characterize the energy efficiency of a manufacturing facility.

Electricity: Electricity is used throughout the manufacturing facility for many different purposes. Some are directly consumed by production activities, e.g., metal forming, air compressing, painting, welding, etc. Others can be non-productive energy consumption such as lighting, ventilation, air conditioning and material handling. Estimating the distribution of energy consumption are 
very rare in manufacturing plants, and only end-use electricity consumption $(\mathrm{kWh})$ is available in most cases.

Natural gas: Natural gas is mainly consumed for space heating and air condition on the plant floor. Some specific manufacturing shops, such as paint shops usually use $50 \%-60 \%$ of the total fuel (or natural gas) in the plants [3]. Water: Water is typically used in multiple processes in automotive manufacturing, e.g., high pressure water jet systems, painting processes, cleaning, heat recovery processes, cooling systems, etc.

Compressed air: Compressed air is widely used in manufacturing plants and is often regarded as the fourth utility after electricity, natural gas and water. However, compressed air is the most costly utility because of its poor efficiency. To use compressed air in a costbeneficial way, the amount of compressed air should be of the minimum quantity and pressure, and used for the shortest possible time. Moreover, the use of compressed air has to be constantly monitored because inadequate maintenance may increase the risks of air leakage and variability in pressure, temperature, moisture level, etc.

Because of the technical limitations, energy waste is inevitably during manufacturing processes in production facilities. These energy wastes take different forms, such as waste heat in gases or liquids, electricity wasted on non-value added processes, etc. In addition, energy efficiency varies from plant to plant because of the differences in types of products produced, facility location, age of facility and equipment condition. These factors introduce variations and present a challenge for benchmarking the energy consumption among plants. This paper presents a novel approach to evaluate energy efficiency and benchmark among peer plants. The results reveal some insights into the reasons for energy inefficiency as well as opportunities to improve energy efficiency for manufacturing facilities.

\subsection{Needs and objectives}

In order to better understand the energy efficiency in the manufacturing sector, plant-level energy efficiency analysis has received great attention from researchers and engineers [4-9]. However, because of the lack of systematic data collection and limited analytics in the manufacturing industry, it has been rare that comprehensive studies of energy efficiency are reported in the literature. Therefore, there is a need to develop a scientific method to measure energy efficiency that indicates where a manufacturing plant lies within a distribution of performance or how far from the industry's best practices the firm is.

The main objective of this paper is to develop a generic model that applies the energy efficiency analysis to energyintensive automotive manufacturing enterprises in order to benchmark the best practice in energy efficiency, and to better understand the root causes of energy inefficiency. A parametric approach is presented which uses a stochastic frontier analysis to obtain the energy efficiency frontier among multiple similar plants, and identify inefficient energy components in these manufacturing plants. This method is illustrated using a case study of a major U.S. automotive engine manufacturer.

\subsection{State-of-the-art}

The energy efficiency analysis is widely used in manufacturing systems and focuses on the efficiency of production process in transforming inputs into outputs. Frontier analysis methods use a boundary to benchmark and identify the efficiency of a single plant relative to a reference set of manufacturing plants. The traditional ordinary least square (OLS) regression methods are no longer appropriate when benchmarking the manufacturer performance in various operating environments. Instead, the existing literature on energy efficiency benchmarking shows that there are mainly two ways to provide benchmarks for comparative efficiency: data envelopment analysis (DEA) and stochastic frontier analysis (SFA). Both are methods of economic modeling for the estimation of production frontiers. However, DEA is a non-parametric method that uses mathematical programming to identify the efficiency frontier and is used for direct peer comparison. The DEA approach has been applied to many studies such as energy use in buildings [10], crop production systems [11], regional productivity in China [12] and energy efficiency in industrial sectors in China [13]. However, DEA method cannot provide a general relationship between inputs and outputs, nor consider statistical noises. Artificial neural network models are also effective for energy benchmarking $[14,15]$ but they have similar drawbacks as DEA.

Stochastic frontier analysis (SFA) is a parametric method for estimating the production frontier in economics. SFA provides a direct estimate of the distribution of efficiency measured relative to the best practice. The advantage of SFA is that it introduces stochastic components to deal with time-varying random factors which affect the energy efficiency for production but are not directly attributable to the producer or the underlying technology. There are many studies extending and applying the SFA model for energy efficiency analysis in agricultural and residential applications. For example, Buck and Young [16] applied SFA to a cross section of Canadian commercial buildings to analyze the factors that affect efficient energy use. Constantin et al. [17] studied the total factor productivity in Brazilian Agribusiness with SFA; Filippini and Hunt [18] estimated the US residential frontier aggregate energy demand in different states with SFA. Zhou et al. [19] utilized SFA to estimate economy-wide energy efficiency performance at a macro-level. Azadeh et al. [20] predicted and analyzed the long-term natural gas consumption behavior in different countries by integrating an adaptive network-based fuzzy interference system (ANFIS) and SFA where ANFIS is used for forecasting while SFA is for examining the behavior of natural gas consumption. 
More recently, several relevant studies have employed SFA to analyze the performance of manufacturing plants. Amornkitvikai and Harvie [21] utilized the SFA and a two-stage DEA approach for a wide range of Thai manufacturing enterprises to predict firm technical efficiency and analyze inefficiency factors in manufacturing plants. Boyd [22] proposed a method to measure the efficiency gap between the average and best practice. He also studied plant-level energy efficiency with a stochastic frontier model $[23,24]$ and estimated the distribution shifting of energy efficiency in US automotive manufacturing plants using SFA [25]. However, these studies only analyzed individual type of energy efficiency while the correlation among different types of energy and the impact of energy performance on the overall manufacturing performance has not yet been fully explored. To fill the gap, this paper proposes a two-stage SFA approach to analyze the energy efficiency both in the form of individual type of energy utility such as electricity, water, compressed air and natural gas, and in terms of aggregated energy utility. This approach extends the methods in [21] and [25] to enable a more comprehensive analysis for energy efficiency performance at the manufacturing plant level. In the first stage, a stochastic production frontier is established by considering the consumption of different utilities and random variations in the plant-specific operating environment. In the second stage, stochastic energy demand frontiers (cost frontiers) are developed for individual utilities and are used to measure how far from the minimal possible energy consumption each plant is. The two-stage SFA approach can characterize the maximum output-production frontier, and the minimum inputsenergy demand frontier under given environment and technologies.

\section{STOCHASTIC FRONTIER MODELS}

A production frontier characterizes the minimum input bundles required to produce various outputs, or the maximum output producible with the input bundles. The stochastic frontier indicates the maximum expected output for various given inputs. The original form of SFA comes from the production function: $P=b L^{\alpha} C^{\beta}, b, \alpha, \beta>0$, where $P$ represents the quantities of output, $b$ is the total factor productivity, $L$ and $C$ represent the labor and capital inputs, respectively. The production function has two fundamental assumptions: (i) $P$ vanishes while either $L$ or $C$ approaches to zero. (ii) constant return to scale, i.e. $\alpha+\beta=1$. Later the Cobb-Douglas functional form of the production function is developed and tested against statistical evidence by Charles Cobb and Paul Douglas [26]. There have been considerable studies that extend and improve the CobbDouglas model. The transcendental logarithmic (translog) production function, a more general form of Cobb Douglas production function, was developed by [27]. Aigner, Lovell and Schmidt [28], and Meeusen and van den Broeck [29] independently extended the model for cross-sectional data by adding two components: one for random noise and one for technical inefficiency effects. Other studies such as Schmidt (1986), Bauer (1990), Battese and Coelli (1992) and Greene (1993) also specified some distributional assumptions for technical inefficiency and considered time-varying technical efficiencies for panel data. Moreover, in order to predict firm-level efficiencies, some studies such as Kumbhakar, Ghosh and McGukin (1991) and Reifschneider and Stevenson (1991), improved the model by expressing the technical inefficiency part as a function with a vector which contains firm-specific variables and a random error [30]. Later Battese and Coelli [31] completed the model with both technical efficiency in the stochastic frontier and time-varying technical inefficiency for panel data.

In this paper, a two-stage SFA approach for energy efficiency analysis is developed based on the existing stochastic frontier models: (i) output efficiency analysis with SFA that measures the distance between the observed and the maximum expected output for given inputs, and (ii) input efficiency analysis with SFA that measures the distance between the observed and the minimum expected inputs for given outputs. The two sub-models provide two different perspectives of the assessment of energy efficiency and measurement for benchmarking. The first sub-model focuses on the overall input effects on the output (productivity) and the technical inefficiency effects are set as truncated normal random variables. The second one isolates the measure of each type of utilities and use frontier analysis to find the gap between the actual energy consumption and the energy demand frontier. This approach is used to help identify the reasons for different efficiency of energy utilization among plants by considering production and plant-specific variables.

\subsection{Output efficiency analysis for production frontier}

In order to estimate the production frontier which is related to different types of utility and influenced by different time-varying plant-specific characteristics, we formulate the problem using the model developed by Battese and Coelli [31].

The Cobb-Douglas Model, a simpler form of SFA model for the production process with multiple types of utilities, is considered first. Given the panel data associated with observations on a sample of $N$ plants over $T$ time periods, the model is defined as:

$$
\begin{aligned}
\ln Y_{i t} & =\beta_{0}+\beta_{1} \ln X_{1 i t}+\beta_{2} \ln X_{2 i t}+\cdots+\beta_{m} \ln X_{m i t}+v_{i t}-u_{i t}, \\
i & =1,2, \ldots, N ; t=1,2, \ldots, T .
\end{aligned}
$$

$Y_{i t}$ is the production volume for $i^{\text {th }}$ plant at time $t$, and $X_{m i t}$ is the type- $m$ utility consumption for $i^{\text {th }}$ plant at time $t$. The parameters $\beta_{m}$ 's are the parameters of technical efficiency 
effects in a linear combination of logarithmic $X_{\text {mit }}$. They can be estimated via maximum likelihood methods which are available in many modern statistical packages (e.g., FRONTIER 4.0). $v_{i t}$ and $u_{i t}$ are different statistical error components in the $i^{\text {th }}$ plant at time $t$.

A general model for the stochastic frontier analysis is in the transcendental logarithmic (translog) form [27], which contains additional second order terms to take the nonlinear relationship between the input and output into account. The generalized expression of translog production function can be expressed as:

$$
\begin{aligned}
\ln Y_{i t}= & \beta_{0}+\beta_{1} \ln X_{1 i t}+\beta_{2} \ln X_{2 i t}+\cdots+\beta_{m} \ln X_{m i t} \\
& +\frac{1}{2} \sum_{n=1}^{N} \sum_{m=1}^{N} \beta_{n m} \ln X_{n i t} \ln X_{m i t}+v_{i t}-u_{i t}
\end{aligned}
$$

where $Y_{i t}$ denotes the production volume for the $i^{\text {th }}$ plant $(i=1,2, \ldots, N)$ at time $t,(t=1,2, \ldots, T) . X_{\text {mit }}$ 's, are the quantity of $m^{\text {th }}$ utility of production associated with the $i^{\text {th }}$ plant at time $t$. $\beta$ 's are unknown parameters associated with the inputs and are to be estimated.

The production frontier with SFA consists of three types of components: (i) energy-productivity effects $\beta_{m} \ln X_{m i t}$, (ii) energy inefficiency effects $u_{i t}$ and (iii) statistical error $v_{i t}$. In particular, $u_{i t}$ and $v_{i t}$ are the 'composed' error terms associated with frontiers. They are composed of a non-negative random component associated with technical inefficiency of production and a traditional symmetric random-noise component, respectively. The inefficiency effect $u_{i t}$ is assumed to be a linear combination of a set of explanatory variables, the $Z_{p i t}$ 's and unknown parameters $\sigma_{p}$ 's. Those explanatory variables are expected to include any variables that can explain the observations that fall short of the corresponding frontier values. The inefficiency effects of the frontier model $u_{i t}$ are specified as follows.

$$
u_{i t}=\sigma_{0}+\sigma_{1} Z_{1 i t}+\sigma_{2} Z_{2 i t}+\sigma_{3} Z_{3 i t}+\cdots+\sigma_{p} Z_{p i t}+w
$$

where $w$ is a truncation of $N\left(0, \sigma_{w}^{2}\right)$ random error term. $Z_{p i t}$ 's are plant-specific variables associated with energy inefficiency such as location, plant age, type of plant, heating degree days (HDD) and cooling degree days (CDD).

In particular, the random errors $v_{i t}$ 's are assumed to follow i.i.d. $N\left(0, \sigma_{v}^{2}\right)$. The stochastic inefficiency effects $u_{i t}$ 's are independently and identically distributed as truncation (at zero) of $N\left(\sigma_{p} Z_{p i t}, \sigma_{u}^{2}\right)$. The purpose of including $u_{i t}$ in the model is to determine plant-specific variables that should be concerned and to estimate the effects of those inefficiency factors on the plant efficiency. Figure 1 illustrates the stochastic production frontier of output $Y$ as a function of a single input, $X$. Different from traditional ordinary regression, SFA model seeks to explain boundary or optimal behavior rather than average behavior as in ordinary least square (OLS) regression model.

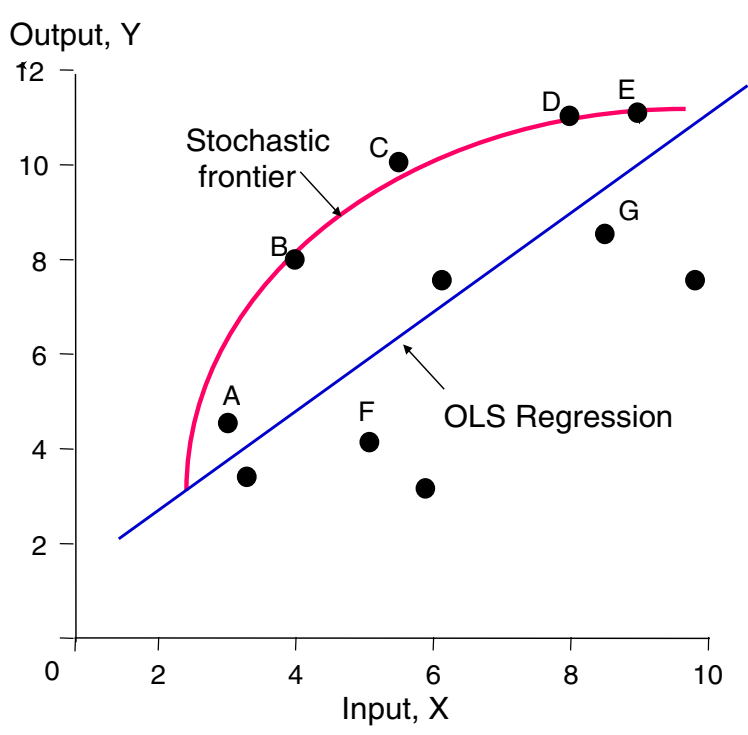

Figure 1. Stochastic production frontier.

The output efficiency is defined as

$$
\text { Eff }_{\text {output }}=\exp (-U)=\frac{\text { Actual units produced }}{\text { Production frontier }}
$$

The output efficiency Eff $_{\text {output }}$ provides an overall efficiency score of utility consumption for each manufacturing plant and the information about how the plant-specific variables affect the efficiency. However, it does not include detailed information about the energy efficiency of a particular type of utility. The second model-input efficiency-is similar to the 'cost frontier' model and can evaluate the relative performance of a particular utility for a specific plant.

\subsection{Input efficiency analysis for energy demand frontier}

In the second model, an input efficiency model is developed to identify the demand frontiers for the individual types of energy based on the results from the first model. The input efficiency model is derived from cost function (dual of production function) because the frontier represents the minimum energy demand. The stochastic cost frontier is specified by simply altering the error term specification from $\left(v_{i t}-u_{i t}\right)$ to $\left(v_{i t}+u_{i t}\right)$ because the inefficiency components $u_{i t}$ 's would cause more energy demand than the stochastic cost frontier rather than cause the plants to operate below the stochastic production frontier. Using the translog model in Battese and Coelli [32], the energy demand frontier model can be specified as follows,

$$
\begin{aligned}
\ln E_{k i t}= & \alpha_{0}+\alpha_{1} \ln P_{i t}+\alpha_{2} \ln Z_{1 i t}+\cdots+\alpha_{p} \ln Z_{p i t} \\
& +\frac{1}{2} \sum_{p=1}^{N} \sum_{q=1}^{N} \alpha_{p q} \ln Z_{p i t} \ln Z_{q i t}+v_{i t}+u_{i t}
\end{aligned}
$$

where $E_{k i t}$ is the total amount of type-k utility consumption (e.g., electricity, water and compressed air) in the $i^{\text {th }}$ plant 
in the $t^{\text {th }}$ period. $P_{i t}$ is the total number of units produced in the $i^{\text {th }}$ plant in the $t^{\text {th }}$ period. $Z_{\text {pit }}$ 's are the plant-specific variables (e.g., plant age, location, climate, etc.). $u_{i t}=u_{i} \exp$ $[-\eta(t-T)]$, where $\eta$ is an unknown scalar parameter and $u_{i}$ 's are non-negative random variable and are assumed to be i.i.d. as a truncated normal distribution with $N\left(\mu, \sigma_{u}^{2}\right) \cdot v_{i t}$ is a random variable that is assumed to be i.i.d. $N\left(0, \sigma_{v}^{2}\right)$ and independent of $u_{i t}$. Now, the input efficiency is defined as

$$
\text { Eff }_{\text {input }}=\exp (U)=\frac{\text { Energy demand frontier }}{\text { Actual energy usage }} .
$$

Based on the results of the input efficiency SFA model, the plant managers can understand how each type of utilities is used in their manufacturing processes and suggest the directions for energy efficiency improvement.

\subsection{Hypothesis test}

The fitness of the above SFA models is evaluated by using hypothesis tests. First, the log likelihood-ratio test is used to identify the model significance, which is shown below:

$$
\mathrm{D}=-2\left[\ln \left(H_{1}\right)-\ln \left(H_{1}\right)\right]
$$

where the null hypothesis $H_{0}$ indicates that in the CobbDouglas form, the parameters of the second order terms are equal to zero, e.g., $\beta_{n m}=0$ for all $n$ and $m$. While the $H_{1}$ is translog production function, e.g., $\beta_{n m} \neq 0$. If the testing result shows that the null hypothesis is strongly rejected at $5 \%$ level of significance, the frontier model in the Cobb-Douglas form is not adequate and the translog form would be more suitable.

Second, a $t$-ratio test is applied to ensure that each technical efficiency component and technical inefficiency component are well placed. In real manufacturing systems, not all types of utility consumption directly contribute to the value-added production. Hence some utilities should be considered as technical inefficiency effects. The null hypothesis tests of every parameter such as $\beta_{m}=0$ for each type of utility are strongly rejected at $5 \%$ level of significance. The existence of quadratic and cross terms needs to be considered to account for the nonlinear relationship between input and output. The null hypothesis for each quadratic or cross term is strongly rejected by $5 \%$ level of significance.

\section{CASE STUDY}

This case study demonstrates the application of the plantlevel energy efficiency frontier analysis using SFA and the benchmarking approach using the two stochastic frontier measures (Eff output $_{\text {and }}$ aff input $_{\text {in }}$ ) described in Section 2. All the plant-level utility data were collected from multiple plants of an original equipment manufacturer (OEM) at worldwide locations.
The data set includes the total production volume, electricity, total water use and compressed air consumption in 12 manufacturing plants over 12 months (i.e. 144 plant-months). Those plants spread all over the world and have different product types. This study classifies the product types into four categories-type I, type II, type III and type IV (Appendix A). The preliminary statistics are shown in Table I. According to the hypothesis testing shown in Appendix B, the final model turns out to be in the translog form. The technical efficiency effects include electricity, total water use and compressed air. For the technical inefficiency effects, latitude that indicates the location of each plant, heating degree days (HDD), cooling degree days (CDD) and gas usage are considered.

\subsection{Overall production frontier using output efficiency model}

First, the output efficiency model described in section 2.1 is applied. The model for total production is

$$
\begin{aligned}
\ln Y= & \beta_{0}+\beta_{1} \ln X_{E}+\beta_{3} \ln X_{A}+\beta_{4} \ln X_{W}+\beta_{5} \ln X_{F} \\
& +\frac{1}{2} \sum_{n=1}^{N} \sum_{m=1}^{M} \beta_{n m} \ln X_{n} \ln X_{m}+v-u
\end{aligned}
$$

where $u=\sigma_{0}+\sigma_{H D D} Z_{H D D}+\sigma_{C D D} Z_{C D D}+\sigma_{L} Z_{L}+\sigma_{F} Z_{F}+$ $\sigma_{\text {year }} Z_{\text {Year }}+\sigma_{G} Z_{G}+w$ and $Y$ is the total production quantity (output).

The SFA method and likelihood-ratio hypotheses test are used to identify the structure and the parameters of both technical efficiency effects and technical inefficiency effects. The estimated parameters are presented in Table II. The levels of significance for all $\beta_{m}$ 's and $\sigma_{p}$ 's are within $5 \%$.

The result turns out that the parameter associated with the usage of electricity $\beta_{E}$ is significantly positive. This implies that the manufacturing plants tend to utilize their electricity effectively in order to improve their technical efficiency for value-added production activities. The consumption of water and compressed air is found to be negatively related to the technical efficiency of the manufacturing plants. The negative parameters for water and compressed air imply that the reported data may not

Table I. Statistics of 12 sample plants in the globe.

\begin{tabular}{llll}
\hline Variable & Sample mean & Std. dev. & Units \\
\hline Number of plants & 12 & - & \\
Number of periods & 12 months & - & \\
Production volume & 26163 & 17849 & \\
Electricity usage (E) & 4004.26 & 3612.03 & $\mathrm{MWh}$ \\
Natural gas (G) & 1507.17 & 3112.99 & $\mathrm{MWh}$ \\
Water (W) & 6560.17 & 9170.65 & $\mathrm{~m}^{3}$ \\
Compressed air (CA) & 169825 & 128546.4635 & $\mathrm{MCF}$ \\
Floor area (F) & 2197185 & 4344163 & $\mathrm{sq} . \mathrm{ft}$ \\
HDD & 191.9 & 206.4 & ${ }^{\circ} \mathrm{C}$ \\
CDD & 65.877 & 82.295 & ${ }^{\circ} \mathrm{C}$ \\
Latitude (L) & 29.99 & 21.3 & \\
\hline
\end{tabular}


Table II. Maximum-likelihood estimates for parameters of stochastic production frontier.

\begin{tabular}{lllcc}
\hline Estimated & Mean & Standard error & T-ratio & Level of significance \\
\hline$\beta_{0}$ & 42.3 & 3.05 & 13.9 & $3.10778 \mathrm{E}-26$ \\
$\beta_{E}$ & 6.61 & 1.02 & 6.46 & $1.43814 \mathrm{E}-09$ \\
$\beta_{W}$ & -6.09 & 0.464 & -13.1 & $1.54158 \mathrm{E}-24$ \\
$\beta_{C A}$ & -6.64 & 0.556 & -12 & $6.45306 \mathrm{E}-22$ \\
$\beta_{E \& E}$ & -0.37 & 0.0645 & -5.74 & $4.25304 \mathrm{E}-08$ \\
$\beta_{W \& W}$ & -0.201 & 0.0288 & -6.99 & $1.11471 \mathrm{E}-10$ \\
$\beta_{C A} \& W$ & 0.812 & 0.0595 & 13.6 & $1.11619 \mathrm{E}-25$ \\
$\sigma_{0}$ & -3.05 & 1.12 & -2.71 & 0.003898027 \\
$\sigma_{F}$ & $3.55 \mathrm{E}-08$ & $7.14 \mathrm{E}-09$ & 4.98 & $1.20612 \mathrm{E}-06$ \\
$\sigma_{H D D}$ & 0.00156 & 0.000577 & 2.7 & 0.00398853 \\
$\sigma_{C D D}$ & 0.00231 & 0.000746 & 3.1 & 0.001222917 \\
$\sigma_{L}$ & 0.0724 & 0.0233 & 3.11 & 0.001204827 \\
$\sigma_{G}$ & -0.0000453 & $2.62 \mathrm{E}-05$ & -1.73 & 0.043652238 \\
\hline
\end{tabular}

reflect the actual volume/amount of resources (water and compressed air) applied to value-added production activities directly. Typically, in a manufacturing plant, water is not only used in manufacturing processes but also in non-production-related activities, e.g., cleaning and cooling, etc. Also, manufacturing plants may not have a precise control or proper maintenance of their compressed air system which may cause leakage problems. These may lead to negative effects on the energy efficiency.

The estimates of the technical inefficiency effects $u_{i t}$ 's indicate that floor area, HDD, $C D D$ and latitude have negative impacts on the production efficiency. The test result of floor area as a technical inefficiency effect indicates that the larger plant tends to have lower efficiency. One possible reason for this is that the proportion of effective production area in the larger plants is lower than that in the smaller plants, causing more wastes of utility usage for cooling and heating.

Figure 2 shows the histogram of energy efficiency relative to the predicted best practice of 12 plants in 12 months. The bars present the number of plant-month, and the solid line represents the cumulative percentage of the efficiency performance. The output efficiency statistics shown in Table III indicate that the median of the output efficiency is about 0.85 and the average output efficiency is about
Table III. Output efficiency histogram statistics result.

Output efficiency histogram table

\begin{tabular}{lcc}
\hline Efficiency & Number of plant-month & Cumulative \% \\
\hline 0.35 & 0 & $0.00 \%$ \\
0.40 & 0 & $0.00 \%$ \\
0.45 & 3 & $2.08 \%$ \\
0.50 & 1 & $2.78 \%$ \\
0.55 & 8 & $8.33 \%$ \\
0.60 & 12 & $16.67 \%$ \\
0.65 & 11 & $24.31 \%$ \\
0.70 & 9 & $30.56 \%$ \\
0.75 & 12 & $38.89 \%$ \\
0.80 & 1 & $39.58 \%$ \\
0.85 & 15 & $50.00 \%$ \\
0.90 & 16 & $61.11 \%$ \\
0.95 & 24 & $77.78 \%$ \\
1.00 & 32 & $100.00 \%$ \\
\hline
\end{tabular}

0.8. Among the 144 plant-months, 32 of them are close to the 'best practice', and half of them have energy efficiency lower than $85 \%$. There are four plant-months that have efficiency lower than $50 \%$.

\section{Output Efficiency Histogram}

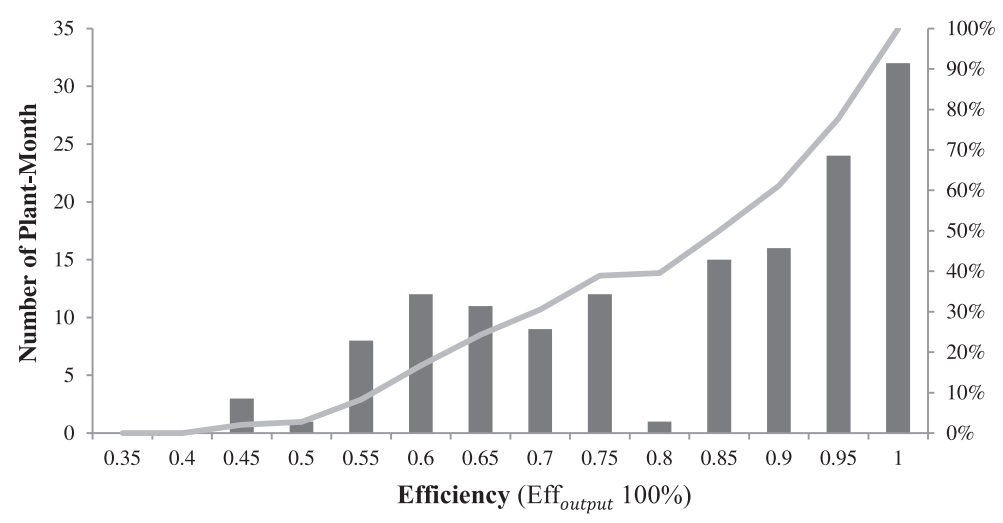

Figure 2. Output efficiency frequency: Eff ${ }_{\text {output }}$. 
The percentage of the production efficiency (output efficiency) with seasonal and yearly data is shown in Figures 3 and 4, respectively. Based on the efficiency evaluation, we categorize all plants into four grades as shown in Appendix A (grade=1 stands for the highest grade in output efficiency). Figure 3 shows that plants 2, 3, and 4 have a similar seasonal trend. The third season has the lowest efficiency while the second season has the highest. Moreover, plants 2, 3, 4 and 6 have the same grade of efficiency. That is, they have similar overall efficiency. Table I shows that the locations of these plants are all within the same regionRegion I. In the same way, plants 7, 8 and 9, all from Region III, also have similar overall efficiency and seasonal behavior. The efficiencies in the first and fourth seasons are lower than those in the second and third seasons. The above observations imply that the regional (latitude) is a significant inefficiency factor of the production energy consumption. Furthermore, Figure 4 presents a yearly ranking of the production efficiency with respect to the multiple utility inputs. It indicates that the energy efficiency is mainly dominated by the regional effects (i.e. latitude and climate) rather than the product type. To sum up, the manufacturing plants from the same geographical region have similar performance in the production efficiency. The positive parameter associated with explanatory variable latitude $\sigma_{L}$ in Table II agrees with this result.

The output efficiency frontier model provides a benchmarking method for the production efficiency of similar manufacturing plants in various regions and climates through aggregated utility inputs. In order to better understand the efficiency and utilization of individual utility, an input efficiency model is described in the next section.

\subsection{Energy efficiency analysis using input efficiency model}

Because of the inherent differences in energy utilization given various plant age, location and technical capability, there is no single number that can represent the true 'best practice' of the energy efficiency. Therefore, it is necessary to use the input efficiency model to explore how efficient the plants are using different types of utilities which are

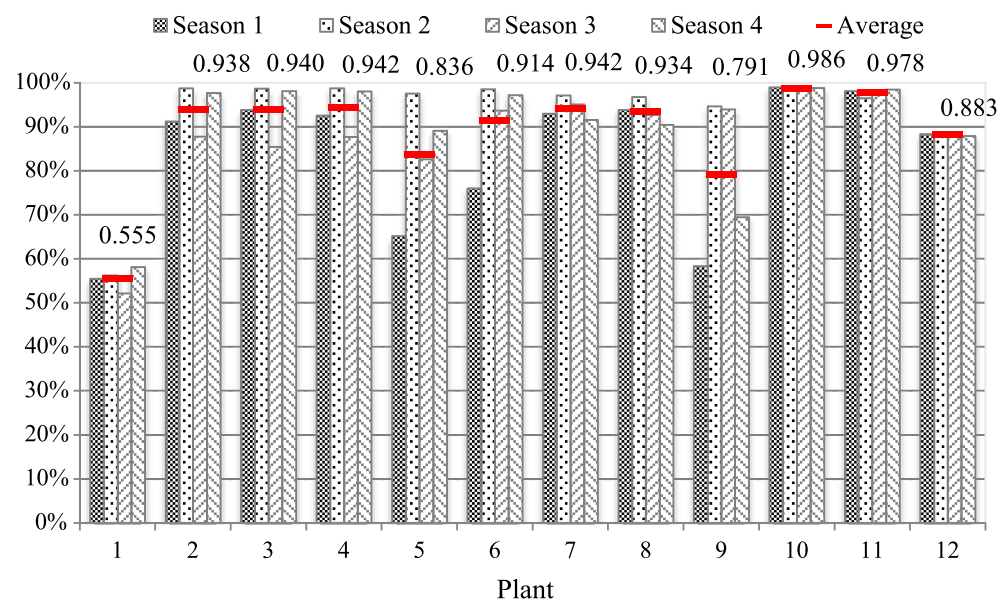

Figure 3. Seasonal energy efficiency of 12 plants.

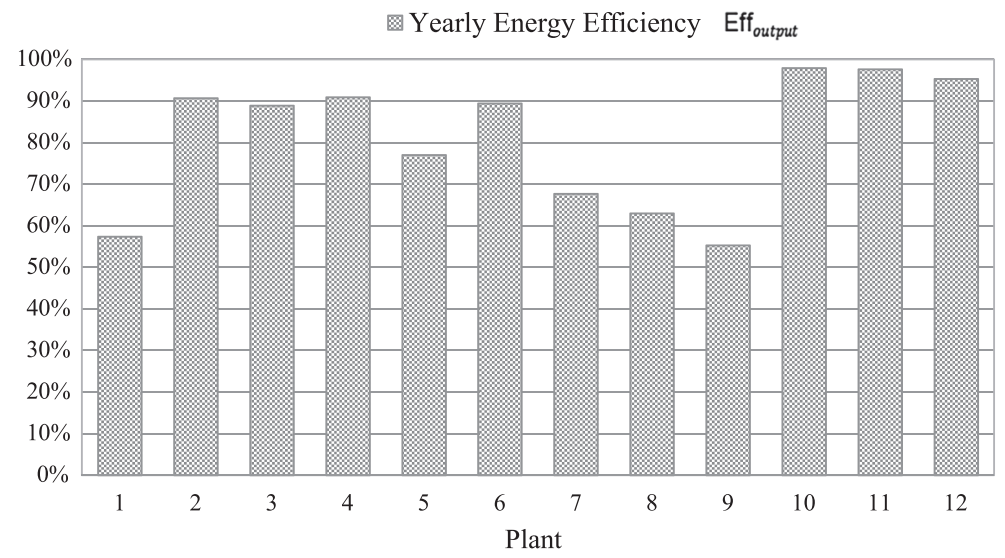

Figure 4. Yearly energy efficiency of 12 plants. 
identified as energy-productivity effects by the first model, and their relative performances to the frontier.

The input efficiency model described in section 2.2 is applied to the same case. For each utility (electricity, water and compressed air), an input efficiency model is developed. For type- $k$ utility, the stochastic frontier model is written as

$$
\begin{aligned}
E_{k}= & \alpha_{0}+\alpha_{Y} \ln Y+\alpha_{F} \ln Z_{F}+\alpha_{H D D} \ln Z_{H D D} \\
& +\alpha_{D D D} \ln Z_{C D D}+\alpha_{L} \ln Z_{L}+\alpha_{\text {year }} \ln Z_{\text {year }} \\
& +\alpha_{G} \ln Z_{G}+\frac{1}{2} \sum_{p=1}^{N} \sum_{q=1}^{N} \alpha_{p q} \ln Z_{p} \ln Z_{q}+u-v
\end{aligned}
$$

where $E_{k}$ is the consumption of type- $k$ utility; $Y$ is the production quantity; $Z_{p}$ 's are the plant-specific non-energy production inputs and $\alpha_{p}$ 's are the parameters to be estimated. It is assumed that the energy inefficiency $u$ yields a truncated normal distribution (non-negative half) because the actual utility consumption will be higher than the 'best practice'. The parameters of Eq. (9) are estimated for each type of utility, as shown in Appendix C. Table IV shows the result of estimated parameters.

For electricity usage, the positive parameter $\alpha_{Y}$ associated with production quantity shown in Table IV implies that the utility use increases as the production volume increases. Based on the input efficiency defined in section 2.2 , it indicates that the plants produce larger volume of production utilize electricity usage more efficiently. In the meanwhile, the parameters with positive values such as year of built and location (latitude) show positive impacts on electricity efficiency. However, the factors with negative parameters such as HDD, CDD and gas usage have adverse effects on electricity efficiency. These results can be explained by the followings. Electricity is the main resource of cooling and heating system. HDD, CDD and gas usage reflect the weather condition such that the larger values of them indicate more intensive cooling/heating. Moreover, larger scale of manufacturing plant with more machines or larger plant area usually requires more cooling/heating so that it does not necessarily have advantages in energy efficiency, especially in electricity

\begin{tabular}{|c|c|c|c|c|}
\hline Estimated parameter & Parameter & Standard error & T-ratio & Level of significance \\
\hline$\alpha_{0}$ & 5540 & 0.999 & 5540 & $5.3 E-246$ \\
\hline$\alpha_{Y}$ & 359 & 0.926 & 388 & $2.4 \mathrm{E}-144$ \\
\hline$\alpha_{F}$ & -54.7 & 0.88 & -62.2 & 7.79E-75 \\
\hline$\alpha_{H D D}$ & -38.8 & 0.982 & -39.5 & $4.34 \mathrm{E}-58$ \\
\hline$\alpha_{C D D}$ & -22.2 & 0.981 & -22.6 & $1.05 \mathrm{E}-38$ \\
\hline$\alpha_{\text {year }}$ & 708 & 0.953 & 743 & $3.4 \mathrm{E}-169$ \\
\hline$\alpha_{L}$ & 918 & 0.983 & 933 & $6.6 \mathrm{E}-178$ \\
\hline$\alpha_{\text {Gas }}$ & -41.9 & 0.975 & -43 & $3.9 \mathrm{E}-61$ \\
\hline$\alpha_{C D D} *$ Year & 2.92 & 0.129 & 22.6 & $9.58 \mathrm{E}-39$ \\
\hline$\alpha_{\text {Year }}{ }^{*} L$ & -115 & 0.288 & -400 & $1.5 E-145$ \\
\hline$\alpha_{H D D} *$ Year & 5.1 & 0.129 & 39.4 & $5.48 E-58$ \\
\hline$\alpha_{\text {Year }}{ }_{\text {Gas }}$ & 5.52 & 0.128 & 43 & $3.4 \mathrm{E}-61$ \\
\hline$\alpha_{F} *$ Year & 8.73 & 0.134 & 65 & $1.71 \mathrm{E}-76$ \\
\hline$\alpha_{Y *} y_{e a r}$ & -47.2 & 0.123 & -384 & $5.3 E-144$ \\
\hline$\alpha_{F * L}$ & -3.13 & 0.144 & -21.7 & $2.51 \mathrm{E}-37$ \\
\hline
\end{tabular}
efficiency. Figure 5 shows the percentage of the electricity

Table IV. Parameters of electricity.

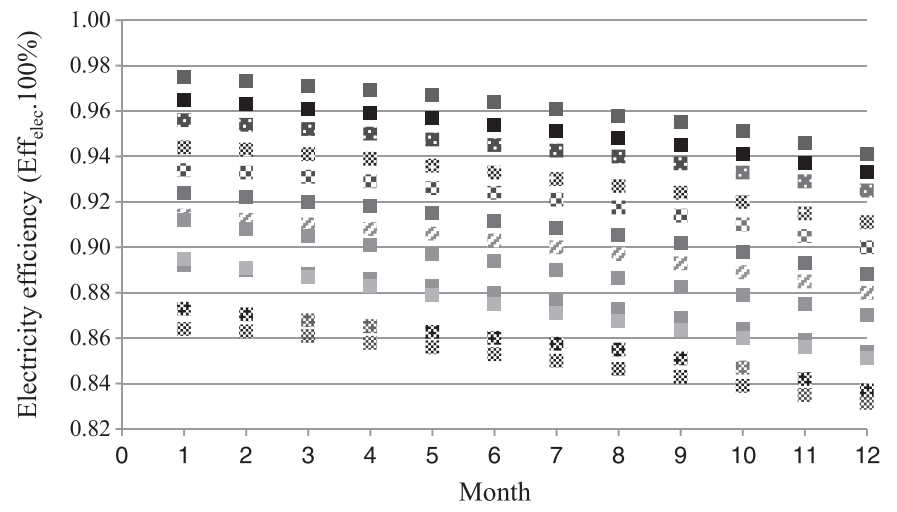

Ranking

Plant 11

Plant 10

Plant 12

Plant 2

Plant 4

Plant 3

Plant 6

Plant 7

Plant 5

Plant 8

Plant 1

Plant 9

Figure 5. Electricity efficiency of 12 plants in 12 months. 
efficiency for 12 plants using the panel data. The figure illustrates the efficiency of electricity relative to the frontier and the ranking of the plants. The ratio of the utility consumption of the best practice to the actual plant utility consumption is defined as the energy efficiency score. It shows that the consistent performance ranking throughout 12 months and the overall performance declines gradually as the time goes on. The first tier of the ranking is composed of plants 10,11 and 12 which are exactly the plants in region IV. This indicates that the plants in this geographical area have the best performance in terms of electricity efficiency during manufacturing processes. The middle tier consists of plants 2, 4, 3 and 6 which are also in the similar region (Region II). Therefore, it implies that electricity efficiency is affected by the regional factor significantly, which is also supported by the large value of latitude parameter.

The benchmarking of energy efficiency using the same method of Eq. (9) is also applied to water use and compressed air usage, respectively (see Figures 6 and 7). By comparing the statistical results of electricity, compressed air and water use shown in Appendix D, we find that the electricity efficiency is much higher than the efficiency of compressed air and water use. This agrees with the parameters of the output efficiency model-positive parameters for electricity while negative parameters for the compressed air and water. Furthermore, from Figures 5, 6 and 7, there is an interesting observation that the plants with 'best performance' in both overall production efficiency and electricity efficiency (i.e. plants 10, 11 and 12) do not perform well in water efficiency and compressed air efficiency. Therefore, the analysis using the input efficiency model becomes necessary and useful because it helps to further pinpoint the inefficient energy components of each plant and potentially provides guidance for energy-related operational improvement.

Example 1. The overall production efficiency and electricity efficiency of plants 10 and 11 have relatively good performance. However, both the efficiency of compressed air and water use of plants 10 and 11 are lower than 50\%. This indicates that there still exist opportunities to improve these two plants even if they have excellent overall production efficiency performance. Therefore, the managers can invest in technologies to continuously improve the water use efficiency as well as the monitoring and maintenance of the compressed air systems.

Example 2. Plant 1 has a relatively poor performance in terms of overall production efficiency and electricity

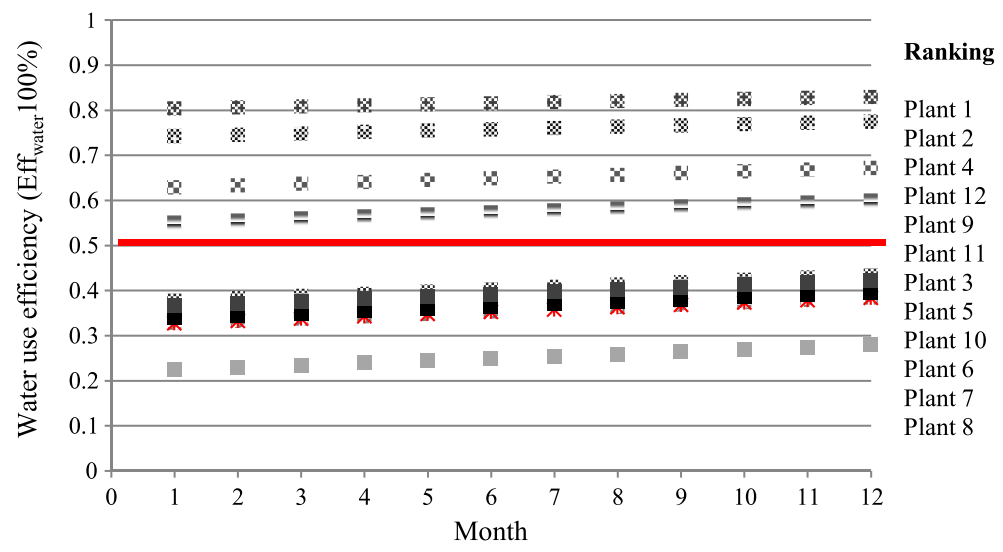

Figure 6. Total water use efficiency of 12 plants in 12 months.

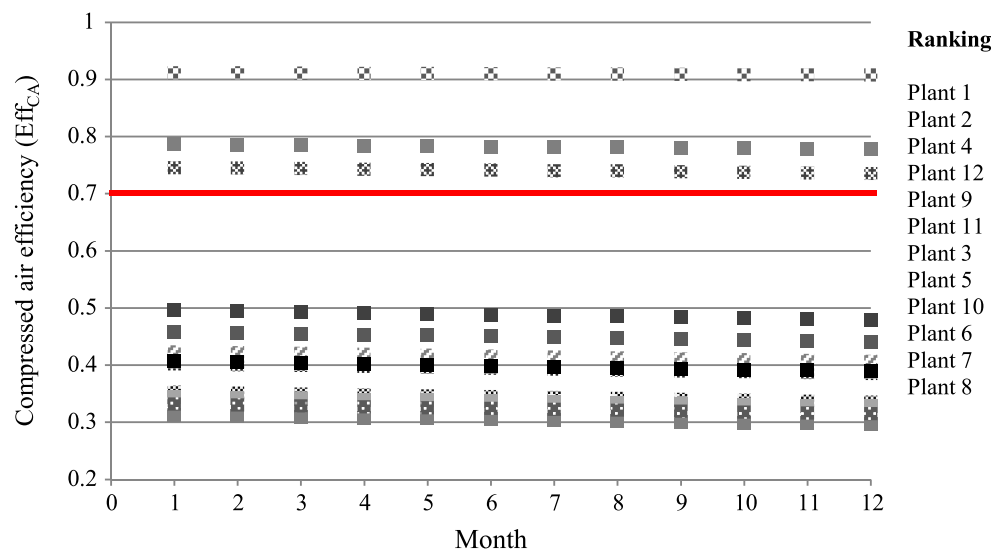

Figure 7. Compressed air usage efficiency of 12 plants in 12 months. 
efficiency. However, it ranks top in compressed air and water efficiency. This provides the plant manager a quick decision support that investing on the electricity performance could potentially improve the overall production efficiency of the plant.

Comparing Figures 5, 6 and 7, we observe that the consumption of electricity, water and compressed air exhibits different seasonality. All plants show a slight decrease over time in electric energy efficiency, implying that the equipment degrades over time. The pattern is not observed in other two types of utilities, indicating that water or compressed air efficiency might have less to do with the seasonality but more to do with other factors such as system configuration or technological variations.

\section{CONCLUSIONS}

This paper presents a two-stage stochastic frontier model for plant-level energy efficiency analysis and benchmarking for automotive manufacturing plants. The two sub-models are developed based on plant-level panel data and a stochastic frontier regression approach. The first sub-model estimates the parameters of both utility inputs and plant-specific variables in the production frontier function. It is advantageous in finding the relationship between various inputs (energy or non-energy related) and production. The second sub-model, input-oriented, is developed to investigate the performance of individual plants relative to their peers for each utility. The result shows the regional or climate effects could have significant impact on the energy efficiency performance, while the plant's size and product type have less effect on the energy consumption efficiency and manufacturing performance. In the specific automotive engine manufacturing plants case study, electricity has higher efficiency than water and compressed air. The analysis can help us to pinpoint the weakness of the shop floor utility consumption and identify the best direction to improve the manufacturing performance and energy utilization of each plant. For those who have low overall production efficiency, improving electricity efficiency may highly increase its manufacturing performance while for those who already have more than $90 \%$ overall production efficiency, the improvement of compressed air system and water utilization could present opportunities for energy savings.

In summary, the integration of the output efficiency model and the input efficiency model provides a complete framework for energy management and benchmarking based on the utility data and plant information. Using the output efficiency model, manufacturing plants are able to evaluate not only their overall plant-level energy efficiency based on the production frontier but also the relationship between plant-specific variables and the production frontier (e.g., age, location, climate, floor area, etc.). The input efficiency model can help the plants identify the relationship between individual types of energy consumption and its inefficient energy effects, and implement more effective energy management programs. The presented method can be easily employed to analyze energy efficiency in other types of automotive manufacturing plants such as assembly plants and transmission plants which involve similar utilities during production. Besides automotive industries, the method is also applicable to other industries to provide information on potential energy efficiency improvement within factory floors by considering main types of energy consumption and plant-specific variables (environmental and technological). The results will advance their understanding of the current status among peers and the achievable levels of energy performance in production-related activities.

\section{Appendix A}

Table A.1. Overall information for each plant.

\begin{tabular}{|c|c|c|c|c|c|c|}
\hline \multirow[t]{2}{*}{ Plant } & \multirow[t]{2}{*}{ Country } & \multirow[t]{2}{*}{ Product type } & \multirow[t]{2}{*}{ Overall efficiency grade } & \multicolumn{3}{|c|}{ Efficiency grade of individual utility } \\
\hline & & & & Electricity & Total water & Compressed air \\
\hline 1 & Region I & Type I & 4 & 11 & 3 & 1 \\
\hline 2 & Region II & Type II & 2 & 4 & 9 & 2 \\
\hline 3 & Region II & Type II & 2 & 6 & 5 & 7 \\
\hline 4 & Region II & Type II & 2 & 5 & 1 & 3 \\
\hline 5 & Region II & Type IV & 3 & 9 & 12 & 8 \\
\hline 6 & Region II & Type II & 2 & 7 & 6 & 10 \\
\hline 7 & Region III & Type I & 3 & 8 & 2 & 11 \\
\hline 8 & Region III & Type III & 3 & 10 & 10 & 12 \\
\hline 9 & Region III & Type III & 4 & 12 & 8 & 5 \\
\hline 10 & Region IV & Type III & 1 & 2 & 7 & 9 \\
\hline 11 & Region IV & Type III & 1 & 1 & 4 & 6 \\
\hline 12 & Region IV & Type II & 2 & 3 & 11 & 4 \\
\hline
\end{tabular}




\section{Appendix B. Likelihood-ratio Hypotheses Tests for Output EfficiencyModel and Input Efficiency Model}

Table B.1.Likelihood-ratio Hypotheses Test for Output Efficiency Model.

\begin{tabular}{lccr}
\hline Null hypothesis & \multicolumn{2}{c}{ Overall production } \\
\cline { 2 - 4 } & LR statistics & Critical value & Decision \\
\hline Cobb-Douglas $\left(H_{0}: \boldsymbol{\beta}_{C A} * T W=\boldsymbol{\beta}_{E} * E=\boldsymbol{\beta}_{T W} * T W=0\right)$ & 51.0 & 6.25 & Reject $H_{0}$ \\
\hline
\end{tabular}

Table B.2: Likelihood-ratio Hypotheses Test for Input Efficiency Model - Electricity.

\begin{tabular}{|c|c|c|c|}
\hline \multirow[t]{2}{*}{ Null hypothesis } & \multicolumn{3}{|c|}{ Electricity } \\
\hline & LR statistics & Critical value & Decision \\
\hline Cobb-Douglas $\left(H_{0}: \alpha_{C D D} *\right.$ Year $=\alpha_{\text {Year }} *$ Latitude $=\alpha_{H D D} *$ Year $=$ & 79.4 & 14.07 & Reject $H_{0}$ \\
\hline $\boldsymbol{\alpha}_{\text {Year }}{ }^{* \text { Gas }}=\boldsymbol{\alpha}_{F A} *$ Year $=\boldsymbol{\alpha}_{Y * \text { Year }}=\boldsymbol{\alpha}_{F A} *$ Latitude $\left.=0\right)$ & & & \\
\hline No stochastic inefficiency $\left(H_{0}: \gamma=0\right)$ & 68.3 & 3.84 & Reject $H_{0}$ \\
\hline
\end{tabular}

Table B.3: Likelihood-ratio Hypotheses Test for Input Efficiency Model - Compressed Air.

\begin{tabular}{|c|c|c|c|}
\hline \multirow[t]{2}{*}{ Null hypothesis } & \multicolumn{3}{|c|}{ Compressed air } \\
\hline & LR statistics & Critical value & Decision \\
\hline Cobb-Douglas $\left(\boldsymbol{H}_{0}: \boldsymbol{\alpha}_{\text {Year }} *\right.$ Latitude $=\boldsymbol{\beta}_{Y} *$ Year $\left.=0\right)$ & 35.3 & 5.99 & Reject $H_{0}$ \\
\hline No HDD, CDD or Gas effects $\left(H_{0}: \boldsymbol{\alpha}_{H D D}=\boldsymbol{\alpha}_{C D D}=\boldsymbol{\alpha}_{G a s}=0\right)$ & -27.7 & $6.25^{*}$ & Not reject $H_{0}$ \\
\hline No inefficiency effects $\left(H_{0}: \gamma=\sigma_{0}=\sigma_{H D D}=\sigma_{C D D}=\sigma_{G a s}=0\right)$ & 13.4 & 11.07 & Reject $H_{0}$ \\
\hline No stochastic inefficiency $\left(H_{0}: \gamma=0\right)$ & 34.1 & 3.84 & Reject $H_{0}$ \\
\hline No inefficiency $\left(H_{0}: \sigma_{0}=\sigma_{H D D}=\sigma_{C D D}=\sigma_{G a s}=0\right)$ & -17.4 & $7.78^{*}$ & Not reject $H_{0}$ \\
\hline
\end{tabular}

Table B.4: Likelihood-ratio Hypotheses Test for Input Efficiency Model - Total Water Use.

\begin{tabular}{|c|c|c|c|}
\hline \multirow[t]{2}{*}{ Null hypothesis } & \multicolumn{3}{|c|}{ Total water use } \\
\hline & LR statistics & Critical value & Decision \\
\hline Cobb-Douglas $\left(H_{0}: \alpha_{Y * F A}=\alpha_{F A} * H D D=\alpha_{C D D} *\right.$ Year $=\alpha_{\text {Year }}{ }^{*}$ Latitude $=$ & 22.96 & 16.92 & Reject $H_{0}$ \\
\hline$\alpha_{H D D} *$ Year $=\alpha_{\text {Year }}{ }_{\text {Gas }}=\alpha_{F A} *$ Year $=\alpha_{Y * \text { Year }}=\alpha_{F A} *$ Latitude $\left.=0\right)$ & & & \\
\hline No stochastic inefficiency $\left(H_{0}: \gamma=0\right)$ & 46.2 & 3.84 & Reject $H_{0}$ \\
\hline
\end{tabular}

\section{Appendix C. Parameters for Input Efficiency Model}

Table C.1: Parameters of input efficiency model - Electricity.

\begin{tabular}{|c|c|c|c|c|}
\hline Estimated & Parameter & Standard error & T-ratio & Level of significance \\
\hline$\alpha_{0}$ & 5540 & 0.999 & 5540 & $5.3 \mathrm{E}-246$ \\
\hline$\alpha_{Y}$ & 359 & 0.926 & 388 & $2.4 \mathrm{E}-144$ \\
\hline$\alpha_{F A}$ & -54.7 & 0.88 & -62.2 & $7.79 E-75$ \\
\hline$\alpha_{H D D}$ & -38.8 & 0.982 & -39.5 & $4.34 \mathrm{E}-58$ \\
\hline$\alpha_{C D D}$ & -22.2 & 0.981 & -22.6 & $1.05 \mathrm{E}-38$ \\
\hline$\alpha_{\text {Year }}$ & 708 & 0.953 & 743 & $3.4 \mathrm{E}-169$ \\
\hline$\alpha_{L}$ & 918 & 0.983 & 933 & $6.6 \mathrm{E}-178$ \\
\hline$\alpha_{\text {Gas }}$ & -41.9 & 0.975 & -43 & $3.9 E-61$ \\
\hline$\alpha_{C D D} *$ year & 2.92 & 0.129 & 22.6 & $9.58 \mathrm{E}-39$ \\
\hline
\end{tabular}


Appendix Table C.1: (Continued)

\begin{tabular}{lcccc}
\hline Estimated & Parameter & Standard error & T-ratio & Level of significance \\
\hline $\boldsymbol{\alpha}_{\text {Year }} *^{*}$ & -115 & 0.288 & -400 & $1.5 \mathrm{E}-145$ \\
$\boldsymbol{\alpha}_{H D D}$ Year & 5.1 & 0.129 & 39.4 & $5.48 \mathrm{E}-58$ \\
$\boldsymbol{\alpha}_{\text {Year }}{ }_{\text {Gas }}$ & 5.52 & 0.128 & 43 & $3.4 \mathrm{E}-61$ \\
$\boldsymbol{\alpha}_{F A}$ Year & 8.73 & 0.134 & 65 & $1.71 \mathrm{E}-76$ \\
$\boldsymbol{\alpha}_{Y * \text { Year }}$ & -47.2 & 0.123 & -384 & $5.3 \mathrm{E}-144$ \\
$\boldsymbol{\alpha}_{F A}{ }^{*}$ & -3.13 & 0.144 & -21.7 & $2.51 \mathrm{E}-37$ \\
\hline
\end{tabular}

Table C.2: Parameters of input efficiency model - Total Water Use.

\begin{tabular}{|c|c|c|c|c|}
\hline Estimated & Parameter & Standard error & T-ratio & Level of significance \\
\hline$\alpha_{0}$ & 7630 & 1.01 & 7540 & 4.7E-255 \\
\hline$\alpha_{Y}$ & 875 & 1.24 & 708 & $1.1 \mathrm{E}-165$ \\
\hline$\alpha_{F A}$ & -190 & 1.43 & -133 & $1.7 \mathrm{E}-102$ \\
\hline$\alpha_{H D D}$ & 53.6 & 1.03 & 52.1 & $1.13 \mathrm{E}-67$ \\
\hline$\alpha_{C D D}$ & -31.1 & 1.05 & -29.7 & $1.21 \mathrm{E}-47$ \\
\hline$\alpha_{\text {Year }}$ & 944 & 1.16 & 814 & $5.6 E-171$ \\
\hline$\alpha_{L}$ & 541 & 1.02 & 528 & $1.4 \mathrm{E}-154$ \\
\hline$\alpha_{\text {Gas }}$ & -22.1 & 1.04 & -21.3 & $1.67 \mathrm{E}-36$ \\
\hline $\boldsymbol{\alpha}_{Y * F A}$ & -0.414 & 0.0728 & -5.68 & $8.65 E-08$ \\
\hline$\alpha_{F A} * H D D$ & -0.141 & 0.0205 & -6.88 & 4.37E-10 \\
\hline$\alpha_{C D D} *$ Year & 4.1 & 0.138 & 29.7 & $1.31 \mathrm{E}-47$ \\
\hline$\alpha_{\text {Year } * L}$ & -56.5 & 0.496 & -114 & $7.82 \mathrm{E}-97$ \\
\hline$\alpha_{H D D} *$ Year & -6.82 & 0.142 & -48.1 & $9.29 E-65$ \\
\hline $\boldsymbol{\alpha}_{\text {Year }}{ }^{\text {Gas }}$ & 2.92 & 0.138 & 21.2 & $1.84 \mathrm{E}-36$ \\
\hline$\alpha_{F A} *$ Year & 29.4 & 0.23 & 128 & 3.7E-101 \\
\hline$\alpha_{Y *}$ Year & -114 & 0.191 & -598 & $2.8 \mathrm{E}-159$ \\
\hline$\alpha_{F A * L}$ & -7.93 & 0.262 & -30.3 & $2.87 \mathrm{E}-48$ \\
\hline
\end{tabular}

Table C.3: Parameters of input efficiency model - Compressed Air.

\begin{tabular}{|c|c|c|c|c|}
\hline Estimated & Parameter & Standard error & T-ratio & Level of significance \\
\hline$\alpha_{0}$ & 6170 & 1.02 & 6070 & $3.6465 E-270$ \\
\hline $\boldsymbol{\alpha}_{Y}$ & 34.8 & 2.84 & 12.2 & $1.45204 \mathrm{E}-21$ \\
\hline$\alpha_{F A}$ & 0.377 & 0.0433 & 8.69 & $4.74846 \mathrm{E}-14$ \\
\hline$\alpha_{\text {Year }}$ & 812 & 0.367 & 2210 & $4.8548 E-228$ \\
\hline$\alpha_{L}$ & 1560 & 1.23 & 1260 & $9.4253 E-205$ \\
\hline$\alpha_{\text {Year } * L}$ & -205 & 0.211 & -970 & $1.0465 E-193$ \\
\hline $\boldsymbol{\alpha}_{Y *}$ Year & -4.5 & 0.377 & -11.9 & $5.38326 \mathrm{E}-21$ \\
\hline
\end{tabular}


Appendix D. Distribution of Input Efficiency Eff elec.,Eff $_{\text {CA.,Eff }}$ water-

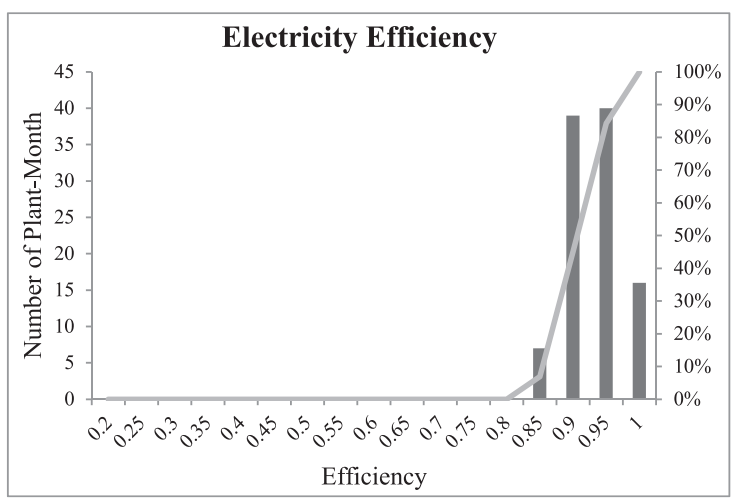

Figure D1. Input efficiency frequency: Eff elec.

Table D. 1: Input Efficiency Histogram Statistics Result - Electricity.

\begin{tabular}{lcc}
\hline \multicolumn{3}{c}{ Electricity histogram table } \\
\hline Efficiency & \# of plant-month & Cumulative $\%$ \\
0.2 & 0 & $0.00 \%$ \\
0.25 & 0 & $0.00 \%$ \\
0.3 & 0 & $0.00 \%$ \\
0.35 & 0 & $0.00 \%$ \\
0.4 & 0 & $0.00 \%$ \\
0.45 & 0 & $0.00 \%$ \\
0.5 & 0 & $0.00 \%$ \\
0.55 & 0 & $0.00 \%$ \\
0.6 & 0 & $0.00 \%$ \\
0.65 & 0 & $0.00 \%$ \\
0.7 & 0 & $0.00 \%$ \\
0.75 & 0 & $0.00 \%$ \\
0.8 & 0 & $0.00 \%$ \\
0.85 & 7 & $6.86 \%$ \\
0.9 & $0.10 \%$ \\
0.95 & 39 & $85.31 \%$ \\
1 & 40 & $100.00 \%$ \\
\hline
\end{tabular}

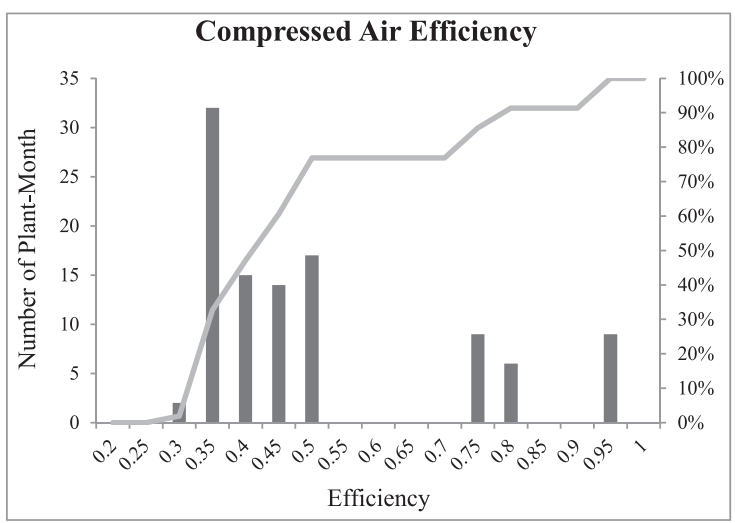

Figure D2. Input efficiency frequency: $\mathrm{Eff}_{\mathrm{CA}}$.
Table D.2: Input Efficiency Histogram Statistics Result - Compressed Air. Compressed air histogram table

\begin{tabular}{lcc}
\hline Efficiency & \# of plant-month & Cumulative \% \\
0.2 & 0 & $0.00 \%$ \\
0.25 & 0 & $0.00 \%$ \\
0.3 & 2 & $1.92 \%$ \\
0.35 & 32 & $32.69 \%$ \\
0.4 & 15 & $47.12 \%$ \\
0.45 & 14 & $60.58 \%$ \\
0.5 & 17 & $76.92 \%$ \\
0.55 & 0 & $76.92 \%$ \\
0.6 & 0 & $76.92 \%$ \\
0.65 & 0 & $76.92 \%$ \\
0.7 & 0 & $76.92 \%$ \\
0.75 & 9 & $85.58 \%$ \\
0.8 & 9 & $91.35 \%$ \\
0.85 & 6 & $91.35 \%$ \\
0.9 & 0 & $91.35 \%$ \\
0.95 & 0 & $100.00 \%$ \\
1 & 9 & $100.00 \%$ \\
\hline
\end{tabular}

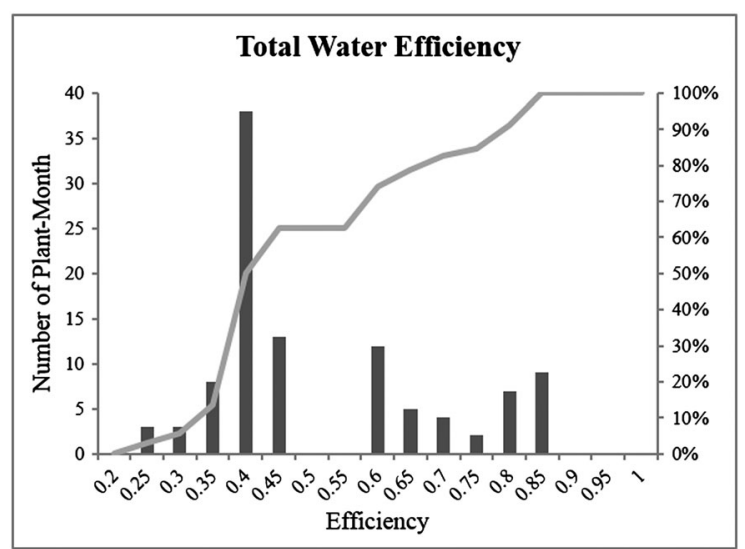

Figure D3. Input efficiency frequency: Eff water.

Table D.3: Input Efficiency Histogram Statistics Result - Total Water Use.

Total water histogram table

\begin{tabular}{lcc}
\hline Efficiency & \# of plant-month & Cumulative \% \\
0.2 & 0 & $0.00 \%$ \\
0.25 & 3 & $2.88 \%$ \\
0.3 & 3 & $5.77 \%$ \\
0.35 & 8 & $13.46 \%$ \\
0.4 & 38 & $50.00 \%$ \\
0.45 & 13 & $62.50 \%$ \\
0.5 & 0 & $62.50 \%$ \\
0.55 & 0 & $62.50 \%$ \\
0.6 & 12 & $74.04 \%$ \\
0.65 & 5 & $78.85 \%$ \\
0.7 & 4 & $82.69 \%$ \\
0.75 & 2 & $84.62 \%$ \\
0.8 & 7 & $91.35 \%$ \\
0.85 & 9 & $100.00 \%$ \\
0.9 & 0 & $100.00 \%$ \\
0.95 & 0 & $100.00 \%$ \\
1 & 0 & $100.00 \%$ \\
\hline
\end{tabular}




\section{REFERENCE}

1. Technology Roadmap for Energy Reduction in Automotive Manufacturing, U.S. Department of Energy, Office of Energy Efficiency \& Renewable Energy Industrial Technologies Program, U.S Council for Automotive Research 2008.

2. Trends in Selected Manufacturing Sectors. Opportunities and challenges for environmentally preferable energy outcomes. U.S. Environmental Protection Agency 2007.

3. Leven B, Weber C. Energy efficiency in innovative industries: application and benefits of energy indicators in the automobile industry, 2001 ACEEE Summer Study on Energy Efficiency in Industry Proceedings Volume 1. American Council for an Energy-Efficient Economy (ACEEE), Washington, D.C. 2001; 67-75.

4. Neelis M, Ramirez A, Patel M, Farla J, Boonekamp P, Blok K. Energy efficiency developments in the Dutch energy-intensive manufacturing industry 1980-2003. Energy Policy 2007; 35.12:6112-6131.

5. Al-Ghandoor A, Phelan PE, Villalobos R, Phelan BE. Modeling and forecasting the U.S. manufacturing aggregate energy intensity. International Journal of Energy Research 2008; 32.6:50-513.

6. Dincer I, Hussain MM, Al-Zaharnah I. Analysis of sectoral energy and exergy use of Saudi Arabia. International Journal of Energy Research 2004; 28.3:205-243.

7. Boyd G, Pang J. Estimating the linkage between energy efficiency and productivity. Energy Policy 2000; 28.5:289-296.

8. Galitsky C, Worrell E. Energy efficiency improvement and cost saving opportunities for the vehicle assembly industry: an ENERGY STAR guide for energy and plant managers, Orlando Lawrence Berkeley National Laboratory 2008; [LBNL-50939].

9. Aguirre F, Villalobos JR, Phelan PE, Pacheco R. Assessing the relative efficiency of energy use among similar manufacturing industries. International Journal of Energy Research 2011; 35.6:477-488.

10. Ferrier JD, Hirschberg JG. Climate control efficiency. The Energy Journal 1992; 13.1:37-54.

11. Nassiri SM, Singh S. Study on energy use efficiency for paddy crop using data envelopment analysis (DEA) technique. Applied Energy 2009; 86.7-8:1320-1325.

12. Hu JL, Wang SC. Total-factor energy efficiency of regions in China. Energy Policy 2006; 34.17:3206-3217.

13. Chang TP, Hu JL. Total-factor energy productivity growth, technical progress, and efficiency change: an empirical study of China. Applied Energy 2010; 87.10:3262-3270.

14. Yalcintas M. An energy benchmarking model based on artificial neural network method with a case example for tropical climates. International Journal of Energy Research 2006; 30.14:1158-1174.

15. Yalcintas M, Ozturk UA. An energy benchmarking model based on artificial neural network method utilizing US Commercial Buildings Energy Consumption Survey (CBECS) database. International Journal of Energy Research 2007; 31.4:412-421.

16. Buck J, Young D. The potential for energy efficiency gains in the Canadian commercial building sector: a stochastic frontier study. Energy 2007; 32.9:1769-1780.

17. Constantin PD, Martin DL, de Rivera y Rivera EBB. Cobb-Douglas, translog stochastic production function and data envelopment analysis in total factor productivity in Brazilian agribusiness. Journal of Operations and supply Chain Management 2009; 2.2:20-34.

18. Filippini M, Hunt LC. US residential energy demand and energy efficiency: a stochastic demand frontier approach. Energy Economics 2012; 34.5:1484-1491.

19. Zhou P, Ang BW, Zhou DQ. Measuring economy-wide energy efficiency performance: a parametric frontier approach. Applied Energy 2011; 90.1:196-200.

20. Azadeh A, Asadzadeh SM, Nadimi V, Tajvidi A, Sheikalishahi M. A neuro fuzzy stochastic frontier analysis approach for long-term natural gas consumption forecasting and behavior analysis: the cases of Bahrain. Saudi Arabia, Syria, and UAE, Applied Energy 2011; 88.11:3850-3859.

21. Amornkitvikai Y, Harvie C. Measuring technical inefficiency factors for Thai listed manufacturing enterprises: a stochastic frontier (SFA) and data envelopment analysis (DEA). Australian Conference of Economists 2010:1-29.

22. Boyd GA. A method for measuring the efficiency gap between average and best practice energy use. Journal of Industrial Ecology 2005; 9.3:51-65.

23. Boyd GA. Estimating plant level energy efficiency with a stochastic frontier. The Energy Journal 2008; 29.2:23-43.

24. Boyd G, Dutrow E, Tunnessen W. The evolution of the ENERGY STAR energy performance indicator for benchmarking industrial plant manufacturing energy use. Journal of Cleaner Production 2008; 16.6:708-715.

25. Boyd GA. Estimating the changes in the distribution of energy efficiency in the U.S. automobile assembly industry. Energy Economics 2014; 42:81-87.

26. Charles WC, Paul HD. A theory of production. The American Economic Review March 1928; 18.1:139-165.

27. Christensen LR, Jorgenson DW, Lau LJ. Transcendental logarithmic production frontiers. The Review of Economics and Statistics 1973; 55.1:28-45.

28. Aigner D, Lovell CAK, Schmidt P. Formulation and estimation of stochastic frontier production function models. Journal of Econometrics 1976; 6.1:21-37. 
29. Meeusen W, Van den Broeck J. Efficiency estimation from Cobb-Douglas production function with composed error. International Economic Review 1977; 18.2:435-444.

30. Kumbhakar SC, Lovell CAK. Stochastic Frontier Analysis. University of Cambridge Pres: Cambridge, 2000.
31. Battese GE, Coelli TJ. A model of technical inefficiency effects in a stochastic production function for panel data. Empirical Economics 1995; 20.2:325-332.

32. Battese GE, Coelli TJ. Frontier production functions, technical efficiency and panel data: with application to paddy farmers in India. Journal of Productivity Analysis 1992; 3:153-169. 